\title{
Fatores que Influenciaram a Participação no Ensino Profissionalizante: uma análise da política pública das escolas estaduais de ensino profissionalizante (EEEP) do estado do Ceará
}

\author{
Natália de Olivindo Souza \\ (Mestranda pelo curso de Economia Aplicada da Faculdade de Economia, Administração e \\ Contabilidade, FEAC, UFAL.) \\ Karine Daniele da Silva \\ (Mestranda pelo curso de Economia Aplicada da Faculdade de Economia, Administração e \\ Contabilidade, FEAC, UFAL.)
}

\begin{abstract}
Resumo:
Dentre as políticas educacionais, chama atenção a política de inserção de Escolas Estaduais de Educação Profissionalizante (EEEP) no estado do Ceará. O objetivo deste estudo é analisar os fatores que podem estar relacionados ao ingresso dos estudantes no ensino profissionalizante das EEEP. Nesse tocante, foi utilizado um modelo de resposta binária Logit. Variáveis pessoais do aluno, condição socioeconômica, nível educacional dos pais e de infraestrutura das escolas foram colhidas através de dados do INEP e SEDUC. Destacase que, quanto maior a idade, se este ser for homem e tiver pai e mãe com educação até o fundamental, menor é a probabilidade de o aluno pertencer a uma EEEP; em contrapartida, se for solteiro, tiver mãe com ensino superior, maior condição socioeconômica e de infraestrutura escolar, maior é essa probabilidade. O trabalho reconhece características dessa política educacional e abre caminho para novas discussões.
\end{abstract}

Palavras-Chaves: Educação, Ensino Profissionalizante, Logit.

\begin{abstract}
:
Among the educational policies, it is worth mentioning the policy of insertion of State Schools of Vocational Education (EEEP) in the state of Ceará. The objective of this study is to analyze the factors that may be related to the students' entrance in the vocational training of EEEP. In this respect, a Logit binary response model was used. Student's personal variables, socioeconomic condition, parental educational level and school infrastructure were collected through data from INEP and SEDUC. It is emphasized that, the greater the age, if this being is male and has educated parents to the fundamental, reduces the probability of the student belonging to an EEEP; On the other hand, if he is single, he has a mother with higher education, a higher socioeconomic condition and a school infrastructure, this probability increases. The work recognizes the characteristics of this educational policy and opens the way to new discussions.
\end{abstract}

Keywords: Education, Vocational Education, Logit. 


\section{1) INTRODUÇÃO}

Por ser considerada uma área estratégica e indispensável ao desenvolvimento, a educação é um dos campos mais suscetíveis à inserção de políticas públicas. Dessa forma, a análise de fatores ligados a políticas educacionais é relevante para redimensionar ações, auxiliar na tomada de decisão, evitar onerosidades monetárias e sociais, além de provocar maior focalização em necessidades específicas que possam resultar em melhoras significativas na educação.

Ao se tratar do Brasil, apesar do aumento significativo nos investimentos em educação das últimas décadas, este apresenta indicadores alarmantes, especialmente no que se refere à proficiência dos alunos (TAVARES, 2014). Esse fato, além de ser preocupante na atualidade, já motivou diversas ações que consideraram novas práticas educacionais a partir de objetivos determinados. Muitas políticas desenvolvidas acabaram se encorpando a estratégias ligadas também à formulação de ocupações e "preparação" da força de trabalho, como foi o caso do ensino profissionalizante.

O primeiro ato que pode ser relacionado ao ensino profissionalizante no Brasil foi a criação do Colégio de Fábricas, em 1809, o qual disponibilizava ensino primário e ensinava ofícios aos estudantes (MARTINS, 2012; BARROS, 2013). A partir desse momento, muitas outras instituições foram criadas pelo governo e pelo setor privado com o intuito de promover esse tipo de ensino. Tal prática, no entanto, geralmente foi cercada pela discussão e referência à "dualidade" existente entre ensino regular e o profissional. Nessa dualidade o ensino regular seria voltado à elite com ênfase a sua preparação para entrada na universidade, enquanto o ensino profissionalizante se direcionava aos filhos dos trabalhadores (CASTRO; TIEZZI, 2005; MARTINS, 2012; MOEHLECKE, 2012).

No entanto, a partir da implantação da primeira Lei de Diretrizes e Bases da Educação Nacional no ano de 1961, um dos focos da escola de educação profissional também passou a ser a entrada do aluno à universidade, dispersando sobremaneira a dualidade referida (CASTRO; TIEZZI, 2005; MARTINS, 2012; MOEHLECKE, 2012).

Das práticas mais contemporâneas a respeito do ensino profissionalizante, pode-se destacar que, a partir do ano de 2008, o Governo Estadual do Ceará iniciou um projeto de criação de Escolas Estaduais de Educação Profissionalizante (EEEP). Estas escolas contam com ensino em 
horário integral e uma grade formada pelas disciplinas básicas do currículo do ensino médio e cursos técnicos profissionalizantes voltados para diversas áreas, além de disciplinas voltadas à formação pessoal e convívio com a sociedade. Essa ação possibilita que o aluno ao mesmo tempo em que conclua o ensino médio também esteja se profissionalizando para o mercado de trabalho, contando como primeira experiência profissional o estágio obrigatório na área cursada e que se realiza no último ano de participação na escola.

No ano de 2013, ano em que se tratam os dados desta pesquisa, existiam 112 EEEP que contavam com 53 cursos técnicos em áreas como saúde, agricultura, computação, finanças, entre outros. De acordo com a Secretaria de Educação do Ceará (SEDUC) (2017), os cursos são escolhidos conforme a realidade local da cidade onde a EEEP é implantada. Os alunos atendidos pelas EEEP no ano de 2013 somavam aproximadamente quarenta mil, cerca de $10 \%$ dos alunos da rede pública que cursavam o ensino médio no estado. O número de escolas aumentou para 116 no ano de 2017, atendendo um maior número de estudantes.

A maior integralidade do ensino profissionalizante pode ser destacada pelas referências direcionadas às EEEP. Silva (2013) considerou, em um informe do Instituto de Pesquisa e Estratégia Econômica do Ceará (IPECE), que a melhora no desempenho do estado na participação no Exame Nacional do Ensino Médio (ENEM), no período 2009-2011, pode ser atrelada à maior participação e bom desempenho dos alunos das EEEP do estado. Destaca-se que no ENEM do período 2009-2012, 29 EEEP tiveram médias melhores ou iguais à média nacional, além de 33 EEEP que estavam entre as 50 melhores escolas do Ceará. Trabalhos posteriores de fato mostraram que os alunos das EEEP apresentaram melhor desempenho e maiores chances de ingressar no ensino superior (MARIANO; ARRAES; SOUZA, 2015; MARIANO; ARRAES; BARBOSA; 2016).

Assim, é interessante a existência de pesquisas que também verifiquem quais fatores interferem na escolha pelo ensino profissionalizante, visto que esse fato é uma escolha por parte do estudante e de sua família. Tal ação possibilita, também, conhecer o perfil dos estudantes que fazem parte das EEEP. Dentro desse foco, o presente trabalho tem o objetivo de analisar os fatores que podem estar relacionados ao ingresso dos estudantes no ensino profissionalizante das EEEP. Para isso será estimado o modelo de resposta binária Logit para verificar as chances e o efeito marginal de os estudantes pertencerem às escolas profissionalizantes. 
A contribuição deste trabalho está em acrescentar informações a trabalhos de avaliação de políticas públicas em que se procurou captar o efeito da política de profissionalização das EEEP, direcionando aqui a visão ao indivíduo tratado, além disso, contribuir para que políticas mais específicas possam ser formuladas para aperfeiçoar os objetivos de uma educação mais inclusiva e efetiva.

O presente artigo divide-se em mais 3 seções, além desta introdução. A seção 2 apresenta o marco teórico que contempla informações acerca das políticas públicas educacionais, notadamente a política de ensino profissionalizante e as EEEP do Ceará. A terceira seção exibe a metodologia utilizada e na seção 4 são apresentados e discutidos os resultados encontrados. As considerações finais concluem o texto.

\section{2) REFERENCIAL TEÓRICO}

\section{1) Políticas Públicas Educacionais}

As políticas públicas ligadas às áreas básicas de desenvolvimento da sociedade, assim como a educação, dada a sua contribuição ao desenvolvimento econômico dos países, são assuntos muito atuais. Diversas pesquisas dedicam-se à mensuração da eficiência de políticas públicas voltadas à educação e aos resultados gerados por sua execução.

A partir das décadas de 80 e 90 alguns países iniciaram processos para avaliar seu sistema de educação, fazer reformulações e implantar políticas públicas no intuito de melhorar a proficiência dos alunos. Os Estados Unidos e a Inglaterra foram os pioneiros na criação da política de Accountability e, embora estivessem em situações políticas e econômicas distintas, seus governos acreditavam que a competitividade econômica internacional estava relacionada a um sistema de educação de qualidade (BROOKE, 2006).

Além de avistar essa relação, os países desenvolvidos têm maiores condições de investimento e execução de políticas de qualidade que objetivem a eficiência do sistema de ensino. Contudo, muitos países em desenvolvimento também têm buscado seguir esse caminho, o que não faz com que as dificuldades enfrentadas sejam poucas, como no caso do Brasil, em que muitas evidências tornam claro que o sistema de educação está ainda longe do ideal. 
Ao que se refere às práticas adotadas para acompanhamento de políticas educacionais, o sistema de avaliação das escolas participantes das políticas de responsabilização, geralmente incluem testes realizados pelos alunos e que refletem se houve ou não avanço no aprendizado. Dependendo do objetivo, o sistema que formulou a política pode responsabilizar a escola, os gestores e professores pelos resultados obtidos. Porém, de acordo com Brooke (2006), para ter organização no ato de inserir políticas desse tipo, é necessário que sejam estabelecidos parâmetros de como as escolas serão avaliadas, como os testes serão implantados, como os resultados serão utilizados, esclarecidos e no que estes servirão, ou seja, quais as penalidades ou benefícios resultarão destes.

Brooke (2006) e Andrade (2008) concordam que a política voltada para a educação que se mostra como mais eficiente é aquela em que a gestão e professores são responsabilizados pelos resultados dos alunos e recebem bonificações como forma de incentivo ao trabalho. Contudo, esse fato não pode ser generalizado e o incentivo monetário nem sempre resulta em respostas positivas e de sucesso nas práticas educacionais.

A exemplo, é possível destacar que pesquisas sobre responsabilização e acompanhamento da educação se intensificaram no século XXI. Um exemplo mundial é a pesquisa de Carnoy, Loeb e Smith (2001), realizada no estado do Texas nos Estados Unidos e que comprovou que a década de 90 foi marcada por muitos avanços em seu sistema educacional. O avanço foi relacionado à aplicação de testes de proficiência, chamados TASS, como forma de acompanhar a vida escolar dos alunos, mas que para muitos críticos essa prática de avaliação teria sido o motivo de forte evasão escolar na época. Com o objetivo de esclarecer esses embates, o trabalho através de métodos de estimação conseguiu mostrar que na realidade, o aumento dos resultados positivos do teste diminuiu a taxa de abandono escolar, especialmente nas escolas mais pobres que procuram melhorar seus resultados.

Para o caso do Brasil é possível mencionar que não existe uma política de Accountability que possa ser comparada com a implantada nos Estados Unidos (ANDRADE, 2008). No entanto, há indícios de desenvolvimento de políticas que procuram avaliar o nível de aprendizado dos estudantes em períodos específicos de sua vida escolar, como exemplo, do Sistema de Avaliação de Educação Básica (SAEB), que estabelece os testes de Avaliação Nacional de Alfabetização (ANA), de Avaliação Nacional da Educação Básica (ANEB), Avaliação Nacional do Rendimento Escolar (Prova Brasil) e que geralmente são aplicados ao $1^{\circ}, 5^{\circ}$ e $9^{\circ}$ anos do ensino fundamental, 
agregando conteúdos de português e matemática. O maior exemplo para o ensino médio é o Exame Nacional do Ensino Médio (ENEM), que avalia os estudantes nas quatro áreas básicas do conhecimento: Matemática e suas tecnologias, Ciências da Natureza e suas tecnologias, Ciências Humanas e suas tecnologias e Linguagens, códigos e suas tecnologias, além de prova de redação, que foca temas atuais. Esse também é considerado a maior "porta de entrada" para a universidade pública e privada no país, sendo o ensino médio dedicado principalmente ao seu conteúdo.

Em relação às avaliações educacionais externas, o Programa Internacional de Avaliação de Alunos (PISA) analisa a situação da educação mundial através do desempenho dos alunos nas disciplinas de leitura, matemática e ciências. O Brasil foi um dos 70 países que participaram desta avaliação em sua última edição no ano de 2015, ficando em uma colocação nada agradável. Desta vez na $59^{\circ}$ posição no que se refere à leitura, $66^{\circ} \mathrm{em}$ matemática e $63^{\circ}$ em ciências, mostrando uma piora em relação à avaliação do ano de 2012. Os baixos resultados, contudo, não constituem novidade. Vieira (2007) já havia citado que em 2000, 2003 e 2006 os resultados foram preocupantes para o Brasil e que era urgente rever essa situação.

Em busca de minimizar as falhas educacionais, muitas iniciativas se estendem aos níveis de educação básica em ordens municipais e estaduais. Nesse sentido, o Prêmio Educacional Escola do Novo Milênio- Educação Básica de Qualidade no Ceará, o Programa Nova Escola do estado do Rio de Janeiro e o Boletim da Escola do estado do Paraná são exemplos de políticas de responsabilização que foram analisadas por Brooke (2006). Embora sejam iniciativas relevantes, foi verificado que essas políticas tiveram pouco impacto no desempenho dos alunos.

Brooke (2006) e Andrade (2008) concordam ainda que as dificuldades para obter resultados nas políticas de educação no Brasil ocorrem por meio da falta de caráter decisório das instâncias responsáveis, tempo insuficiente para amadurecimento da política, dificuldades em comparar as escolas envolvidas e total suscetibilidade de caráter governamental como as mudanças de mandato político.

Apesar dos resultados ainda pouco significativos, Andrade (2008) argumenta que a implantação de políticas educacionais no Brasil seria mais eficiente a nível estadual. A esse respeito, observam-se alguns trabalhos que analisam as políticas nos estados da União, suas experiências, desafios e impactos. Porém, pode-se destacar que as regiões mais pobres enfrentam ainda mais dificuldades em impor um sistema educacional de qualidade 
(VIEIRA, 2007). Isso ocorre porque além dos termos de organização, metas e procedimentos, o fator financeiro é essencial para cobrir os gastos dos projetos e sua execução. Nem todos os países, assim como nem todas as regiões de um mesmo país, têm recursos financeiros suficientes para promover um reajustamento ou modificação total em seu sistema de educação.

A mesma autora, porém, ao analisar a implantação de políticas públicas no estado do Ceará, o reconhece como um dos pioneiros em ações referentes à adoção de programas, projetos e iniciativas voltadas à educação. No cenário nacional, o estado ganhou destaque por ter iniciado a política de responsabilização dos municípios pelo ensino fundamental e a implantação do Fundo de Manutenção e Desenvolvimento do Ensino Fundamental e Valorização do Magistério (FUNDEF). Também é possível verificar que, para um melhor acompanhamento da educação no estado, existe o Sistema Permanente de Avaliação Básica do Estado do Ceará (SPAECE), que atualmente avalia os alunos do ensino fundamental $\left(5^{\circ}\right.$ e $9^{\circ}$ anos) e ensino Médio ( $3^{\circ}$ ano) nas disciplinas Língua Portuguesa e Matemática.

Faz-se necessário, no entanto, conhecer e especificar melhor as políticas em percurso do sistema educacional do país, a exemplo da política de profissionalização das escolas estaduais do Ceará.

\section{2) Ensino Profissionalizante e especificidades do Ensino Profissionalizante no Ceará}

O objetivo de preparar as pessoas para o ingresso no mercado de trabalho ou desempenhar certas funções não é assunto que percorre apenas a atualidade. Segundo Severnini e Orellano (2010), essa prática se dá pela relação existente entre educação, produtividade e desenvolvimento de uma nação. A composição do ensino profissionalizante na educação básica de vários países é também explicada nas palavras de Araújo, Chein e Pinto (2014, p.2): “A educação profissional destaca-se como um fator estratégico de competitividade e desenvolvimento humano na nova ordem econômica mundial".

No entanto, não há como estudar a história do ensino profissionalizante no Brasil sem fazer referência à dualidade que rodeou sua existência e englobar a questão histórica da implantação desse tipo de ensino no país, e no qual o ensino preparatório para o ingresso na universidade seria voltado para a elite, e o profissionalizante, direcionado aos filhos dos 
trabalhadores (CASTRO; TIEZZI, 2005; MARTINS, 2012; MOEHLECKE, 2012).

A situação de ensino profissionalizante ter maior participação de jovens com nível socioeconômico mais baixo também foi comprovada por Foley (2007), na Austrália, através de um trabalho que objetivava estudar o perfil dos participantes do sistema de ensino, e formação profissional do país (VET). Porém, também foi observado que os participantes desse tipo de ensino apresentavam melhores resultados do que a média.

No Brasil, os mesmos autores que fizeram referência à dualidade existente no ensino profissionalizante também diagnosticaram que, depois da criação da primeira Lei de Diretrizes e Bases da Educação Nacional, que ocorreu no ano de 1961, isso viria a mudar, já que essa passou a constituir o ensino profissionalizante juntamente com o ensino médio e estabeleceu que ele tivesse como um de seus propósitos o foco no ensino superior. Logo, já se poderia pensar que os jovens participantes do ensino profissionalizante não seriam prejudicados, pois, além de estarem preparados para o mercado de trabalho, também podem ingressar numa universidade.

Martins (2012) propõe que a escola de ensino técnico e profissionalizante de ensino médio do Brasil seria um dos únicos meios de mudar a mentalidade das pessoas. A escola de ensino profissionalizante também é tida como um meio de promover as habilidades pessoais do jovem, a vivência com as outras pessoas, a inserção no mercado de trabalho e o melhor desempenho nas disciplinas regulares (ARAÚJO; CHEIN; PINTO, 2014).

Nesse sentido, é importante lembrar que as dificuldades referentes ao ensino médio no Brasil são muitas. Moehlecke (2012) lembra que na década de noventa houve uma tentativa de reformulação do ensino médio, incluindo a adoção de ensino profissionalizante, de modo que a região Nordeste do país se apresenta como uma das que têm maior dificuldade em promover um ensino médio adequado. No geral, há problemas com relação ao atraso dos jovens nas séries de referência em relação a sua idade, abandono escolar e repetência.

Em meio a outras iniciativas de políticas educacionais que buscam superar essas dificuldades, a ênfase na promoção da educação profissionalizante no estado do Ceará ocorreu por meio das Escolas Estaduais de Educação Profissional (EEEP), que começou no ano de 2008 e que permitiu a criação 116 EEEP no estado. Juntas atendem mais de cinquenta a mil alunos e promovem mais de 50 cursos técnicos. A parceria para 
construção, manutenção e funcionamento das escolas se faz entre os governos federal e estadual (SEDUC, 2015).

Silva (2013) destaca a participação das EEEP do estado do Ceará no Exame Nacional do Ensino Médio (ENEM) em relação ao desempenho nos anos de 2009 a 2011. O número de participantes do ENEM aumentou no Ceará e, diferentemente do ocorrido em outros estados, o aumento na participação também culminou num ligeiro aumento do desempenho do estado no ranking nacional. Há um otimismo por parte do autor de que a melhora no desempenho do estado possa ser atrelada à maior participação dos alunos das EEEP.

Serviram como evidências para o estudo as informações de que entre as 50 melhores escolas do estado do Ceará, 33 são EEEP e com relação à média de desempenho no ENEM, no ano de 2011, 29 EEEP tiveram médias superiores à média nacional. Se o ranking for entre as 10 melhores escolas do Ceará, $70 \%$ dessas escolas são EEEP do estado. Para o autor:

\begin{abstract}
Em particular, as EEEP não somente se caracterizam por ser uma política de promoção da qualidade do ensino médio, mas também como um claro investimento na formação de capital humano no estado do Ceará que poderá render frutos no médio e longo prazo quando jovens mais qualificados adentrarem no mercado de trabalho (SILVA, 2013, p. 10).
\end{abstract}

Também Mariano, Arraes e Souza (2015) e posteriormente Mariano, Arraes e Barbosa (2016), ao se utilizarem de medidas de avaliação de impacto como a técnica de Propensity Score Matching sobre dados longitudinais dos alunos da rede pública de educação do Ceará, formando os grupos de tratamento e controle, conseguiram captar que os alunos das EEEP apresentam melhores resultados no ENEM do que os alunos das escolas regulares. Tal fato mostrou um efeito significativo do efeito médio do tratamento pela política de profissionalização do estado, que resulta em maiores chances de ingresso no ensino superior.

Partindo da hipótese de que a utilização de políticas públicas é uma das formas para tentar se chegar ao caminho mais coerente para a educação no Brasil (CASTRO; TIEZZI, 2005), além de serem necessários trabalhos que investiguem o impacto dessas políticas para dar um melhor direcionamento da gestão governamental (BARROS; LIMA, 2012), também parece necessário se aferir mais sobre os fatores que têm contribuído para a participação de estudantes no ensino profissionalizante e as características do 
público atingido por esse tipo de ensino, como se fará aqui a partir da metodologia apresentada.

\section{3) METODOLOGIA}

\section{1) Modelo Logit}

Para cumprir os propósitos deste artigo será estimado um modelo logit binário de o aluno pertencer a uma escola profissionalizante (EEEP). A escolha desse modelo não linear de resposta binária se dá pelo fato de a variável dependente $\mathrm{Y}$ possuir valores limitados de 0 e 1 , ou seja, esta variável dicotômica assumirá valor 1 se o estudante pertencer a EEEP e 0 o caso contrário. Wooldridge (2011) mostra que, na maioria das aplicações de modelos de resposta binária, o objetivo primário é explicar os efeitos de $x_{\mathrm{j}}$, sendo esta uma matriz de variáveis dependentes, na probabilidade de resposta $P(y=1 \mid x)$. Assim, os modelos de resposta binária decorrem da seguinte especificação:

$$
P(y=1 \mid x)=G(x \beta) \equiv p(x)
$$

Diferentemente dos modelos de probabilidade linear em que $G(z)=z$ é uma função identidade e onde os resultados das estimativas de um modelo de estimação por Mínimos Quadrados Ordinários (MQO) já podem ser interpretadas como o impacto de uma variável explicativa sobre a variável dependente, mas que o valor de resposta pode fugir à unidade intervalar (0 a 1), nos modelos não lineares acaba por não ocorrer esse problema. Isso porque $G($.$) corresponde à função de distribuição cumulativa e acaba por$ assumir estritamente valores na unidade aberta $0<G(z)<1$ para todo $z \in$ $R$. Assim também a probabilidade de resposta, segundo Wooldridge (2010), é dependente de $x$, pois $p(x)$ é uma função de $x$ e $x \beta=\beta_{1}+\beta_{2} x_{2}+\ldots+\beta_{\mathrm{k}} x_{\mathrm{k}}$.

A função de distribuição logística ao derivar de (1) pode ser representada por:

$$
G(z)=\Lambda \equiv \frac{\exp (z)}{[1+\exp (z)]}
$$


E correspondendo a esse que se chama modelo logit, Gujarati e Porter (2011) também o representam em (3).

$$
P(Y=1 \mid x)=\frac{e^{x \prime \beta}}{1+e^{x \prime \beta}}
$$

$P$ representa a probabilidade de o evento ocorrer ou probabilidade de sucesso, $\mathrm{x}$ representa uma matriz de variáveis independentes, que aqui representam os fatores que se supõe influenciar a participação dos estudantes na EEEP e $\beta$ é o vetor de parâmetros a serem estimados. Um ponto importante decorrente desse modelo e como já introduzido aqui é que por $G$ ser uma função não linear, os coeficientes estimados inicialmente não podem ser interpretados como os efeitos marginais da variável explicativa sobre a variável dependente, pois este irá depender do nível das variáveis da distribuição. Os coeficientes iniciais de um modelo logit dão apenas as direções, ou seja, os efeitos parciais de cada $x_{j}$ na probabilidade de resposta. A estimação é realizada então pelo método da máxima verossimilhança e o modelo logit pode ser expresso pela razão de chances de o indivíduo fazer parte do ensino profissionalizante.

$$
L_{J}=\ln \left(\frac{P_{J}}{1-P_{J}}\right)=Z_{J}=X \beta_{J}
$$

Os coeficientes estimados do logit, contudo, não representam o impacto de uma variável unitária do regressor sobre a probabilidade de interesse, ou seja, não é ainda o efeito marginal. Como apontado por Greene (2008), os coeficientes estimados diretamente somente dão a direção que segue a variação no logit estimado dada variação no regressor referente. $\mathrm{O}$ efeito marginal pode então ser considerado utilizando-se do modelo logit ao se realizar novo cálculo através da distribuição acumulada (encontrando probabilidade predita) e a acrescentando na função de densidade. $O$ efeito marginal pode ainda ser calculado de formas a gerar o Efeito Marginal na Média (EMM) ou Efeito Marginal Médio (MEM). O MEM, que calcula o efeito marginal para os indivíduos médios da amostra, segue a especificação (5) para variáveis contínuas e será aplicado para as variáveis binárias através da especificação (6). 


$$
\begin{gathered}
E x\left[\frac{\partial p(x)}{\partial x j}\right] \\
M E M=\operatorname{Prob}(Y=1, d=1]-\operatorname{Prob}[Y=1, d=0]
\end{gathered}
$$

\section{2) Variáveis e Base de Dados}

Para tratar da participação dos alunos nas EEEP, será feito uso de variáveis independentes relacionadas às características pessoais e socioeconômicas dos alunos e de características das escolas estaduais. As variáveis representativas da condição socioeconômica dos alunos foram extraídas do Instituto Nacional de Estudos e Pesquisas Educacionais Anísio Teixeira (INEP) e as informações sobre infraestrutura das escolas estaduais do Ceará foram obtidas com base no Censo Escolar 2013, totalizando 61888 observações.

As variáveis se dividem em cinco grupos: características pessoais dos alunos, escolaridade do pai, escolaridade da mãe, condição socioeconômica do aluno e características da escola, além da variável eeep, que assume valor 1, caso o aluno pertença a uma escola profissionalizante; 0 , caso contrário. Suas descrições estão representadas no Quadro $n^{\circ} 1$.

\begin{tabular}{|c|c|}
\hline Variáveis & Descrição \\
\hline \multicolumn{2}{|l|}{ Alunos } \\
\hline idade & Anos de idade \\
\hline tpsexo & 1 , se masculino; 0 , caso contrário. \\
\hline tpcorraça & 1 , se branco; 0 , caso contrário. \\
\hline tpestadocivil & 1 , se solteiro; 0 , caso contrário. \\
\hline \multicolumn{2}{|c|}{ Escolaridade Pai } \\
\hline patefund & $\begin{array}{l}\text { 1, se o pai possui escolaridade até o ensino fundamental } \\
\text { completo; } 0 \text {, caso contrário. }\end{array}$ \\
\hline psup & $\begin{array}{l}\text { 1, se o pai possui escolaridade no mínimo o ensino superior } \\
\text { incompleto; } 0 \text {, caso contrário. }\end{array}$ \\
\hline \multicolumn{2}{|c|}{ Escolaridade Mãe } \\
\hline matefund & $\begin{array}{l}\text { 1, se a mãe possui escolaridade até o ensino fundamental } \\
\text { completo; } 0 \text {, caso contrário. }\end{array}$ \\
\hline msup & $\begin{array}{l}\text { 1, se a mãe possui escolaridade no mínimo o ensino superior } \\
\text { incompleto; } 0 \text {, caso contrário. }\end{array}$ \\
\hline
\end{tabular}

Quadro 1: Descrição das variáveis 


\begin{tabular}{ll}
\hline Condições Socioeconômicas \\
\hline ate $2 \mathrm{SM}$ & $\begin{array}{l}\text { 1, se a renda familiar for de até } 2 \text { salários mínimos; } 0 \text {, caso } \\
\text { contrário. }\end{array}$ \\
nse ${ }^{*}$ & Índice de condição socioeconômica do aluno \\
\hline Escolas & \\
\hline infra ${ }^{* *}$ & Índice de infraestrutura da escola \\
\hline
\end{tabular}

Fonte: Elaboração Própria.

Nota (*): Índice criado a partir da análise de componente principal que engloba a existência das seguintes características dos alunos obtidas pelo ENEM 2013: Se possui TV, DVD, rádio, microcomputador, automóvel, máquina de lavar, geladeira, freezer, telefone fixo, celular, acesso à internet, TV por assinatura, aspirador de pó, empregada, banheiro.

(**):Índice gerado pela análise de componentes principais que engloba a existência das seguintes características das escolas obtidas no Censo Escolar 2013: abastecimento de água por rede pública, de esgoto sanitário por rede pública, de coleta periódica de lixo, de sala de diretoria, de sala de professores, de laboratório de informática e de ciências, de quadra de esportes, de cozinha, de biblioteca, de parque infantil, de sanitário adequado a aluno portador de necessidades especiais (PNEs), de dependências e vias adequadas a PNEs, de televisão, de videocassete, de DVD, de parabólica, de copiadora, de retroprojetor, de impressora, de computadores, de acesso à internet, e de alimentação escolar para os alunos.

\section{4) RESULTADO}

\section{1) Análise descritiva dos dados}

A respeito da estatística descritiva das variáveis relacionadas aos alunos do ensino médio da rede pública do estado do Ceará, esta é apresentada na tabela $\mathrm{n}^{\circ} 1$.

Pode-se observar que a média de idade dos alunos das escolas públicas estaduais do Ceará do ano de 2013 era de 18,74 com um desvio padrão de 4,20 anos, mostrando indícios que nas escolas públicas estaduais do Ceará existe distorção de idade série, além de problemas de repetência. Também com relação aos alunos, cerca de $43 \%$ são homens, $95 \%$ solteiros e $19 \%$ se auto declaram brancos. A respeito da educação dos pais, $78 \%$ deles têm até o ensino fundamental completo. Para as mães esse percentual cai para $71 \%$. Esses resultados, juntamente com o aferido para o nível educacional ensino superior em que apenas 3,20\% dos pais e 6,68\% das mães possuem ensino superior pelo menos incompleto, mostram que os pais dos alunos da escola pública do estado têm praticamente uma formação básica. Quanto a fatores socioeconômicos, o índice de condição socioeconômica é de 0,4 , podendo, logo, ser considerado baixo. A isso acrescenta-se a informação que 68,5\% dos alunos possuem renda familiar de até dois salários mínimos. Com relação à variável que faz referência à condição de infraestrutura da escola, essa é de 0,276 . 
Tabela 1: Estatística descritiva das variáveis

\begin{tabular}{ccccc}
\hline Variáveis & Média & $\begin{array}{c}\text { Desvio } \\
\text { Padrão }\end{array}$ & Mínimo & Máximo \\
\hline eeep & 0.1187468 & 0.3234924 & 0 & 1 \\
idade & 18.7427 & 4.204795 & 12 & 80 \\
tpsexo & 0.423806 & 0.4948373 & 0 & 1 \\
tpcorraça & 0.1953529 & 0.2076261 & 0 & 1 \\
tpestadocivil & 0.9548539 & 0.3964753 & 0 & 1 \\
patefund & 0.7851603 & 0.4107144 & 0 & 1 \\
psup & 0.7101861 & 0.4536795 & 0 & 1 \\
matefund & 0.668304 & 0.2497301 & 0 & 1 \\
msup & 0.319993 & 0.1759835 & 0 & 1 \\
ate2SM & 0.6857064 & 0.4642377 & 0 & 1 \\
nse1* & 0,4030014 & 0.1396095 & 0 & 1 \\
infra1** & 0.2761926 & 0.1073235 & 0 & 1 \\
\hline
\end{tabular}

Fonte: SEDUC (2013) e INEP (2013). Elaboração própria.

\section{2) Estimação do logit, razão de chances e efeito marginal}

Em prol de observar como se comportam as variáveis dependentes tomadas para explicar a participação dos alunos na escola profissionalizante, a tabela 2 mostra os resultados do modelo logit estimado. Como a heterocedasticidade é assumida nos modelos de probabilidade não linear, logit e probit, o mais correto é utilizar a versão robusta da regressão que corrige a heterocedasticidade pela matriz var-cov de White e garante a eficiência dos estimadores.

Pelos resultados do logit binário, observa-se que se o indivíduo for mulher, solteira, possuir mãe com escolaridade no nível ensino superior pelo menos incompleto e quanto maiores os índices de condição socioeconômica do aluno e de infraestrutura da escola, maiores serão as chances de esse aluno pertencer à escola profissional. Enquanto isso, quanto maior a idade, menores as chances de pertencer a uma EEEP, isso pode se dar pela necessidade de trabalhar, o que provavelmente não seria possível se eles estudassem em uma escola profissional, já que o ensino é em tempo integral. As chances também diminuem para alunos com pai e mãe com escolaridade até o ensino 
fundamental. As variáveis Raça e Ate2SM foram estatisticamente irrelevantes, considerando nível de significância de 5\%, enquanto conjuntamente as variáveis são estatisticamente significativas e as expectativas tomadas a priori foram atendidas.

Tabela 2: Resultados do modelo Logit

\begin{tabular}{cccc}
\hline EEEP & Coeficiente & Desvio Padrão & p-valor \\
\hline idade & $-0,3187217$ & 0,115525 & 0.000 \\
tpsexo & $-0,1342915$ & 0,0263418 & 0.000 \\
tpcorraça & 0.0201098 & 0.314357 & 0.522 \\
tpestadocivil & 0.6888285 & 0.1375464 & 0.000 \\
patefund & -0.3294295 & 0.0324294 & 0.000 \\
psup & -0.1251277 & 0.0638261 & 0.050 \\
matefund & -0.4061186 & 0.315307 & 0.000 \\
msup & 0.1332516 & 0.456409 & 0.004 \\
ate2SM & -0.0198236 & 0.0297344 & 0.505 \\
nse1* & 1.93357 & 0.99241 & 0.000 \\
infra1** & 1.864242 & 0.110799 & 0.0000 \\
constante & 2.200354 & 0.263008 & 0.000 \\
No de & & & \\
observaçóes & 61888 & & \\
LR chi2 $(\mathbf{1 1})$ & 3902.44 & & \\
Prob> chi2 & 0.0000 & & \\
Pseudo-R2 & 0.0865 & & \\
\hline
\end{tabular}

Fonte: Elaboração própria.

Para se reconhecer as chances de o aluno pertencer à escola profissional, dadas as condições das variáveis explicativas, é possível também dentro da estimação da regressão logística através do uso do antilogaritmo dos coeficientes estimados para o logit, obter a razão de chances ou odds ratio. Pode-se destacar por esses termos que o aumento de um ano na idade do aluno diminui em 0,72 vezes as chances de esse pertencer a uma EEEP, enquanto que, se o indivíduo for solteiro, aumentam as chances de sucesso em aproximadamente 2 vezes em relação aos não solteiros. Esses e os demais resultados estão expostos na tabela 3. 
Tabela 3: Razão de chances

\begin{tabular}{cccc}
\hline EEEP & OddsRatio & Desvio Padrão & p-valor \\
\hline Idade & 0.7270778 & 0.083995 & 0.0000 \\
tp_sexo & 0.8743352 & 0.0230374 & 0.0000 \\
tp_estado_civil & 1.991381 & 0.2739074 & 0.0000 \\
tp_cor_raça & 1.020313 & 0.320743 & 0.522 \\
patfund & 0.719334 & 0.0233275 & 0.0000 \\
matefund & 0.6662311 & 0.210067 & 0.0000 \\
msup & 1.142537 & 0.0521465 & 0.0004 \\
psup & 0.8823842 & 0.0563192 & 0.050 \\
ate2sm & 0.9803716 & 0.0291507 & 0.505 \\
infra1 & 6.451047 & 0.7147697 & 0.0000 \\
nse1 & 6.91415 & 0.6861671 & 0.0000 \\
cons & 9.028213 & 2.374492 & 0.0000 \\
\hline
\end{tabular}

Fonte: Elaboração própria.

No entanto, deve-se destacar que os coeficientes angulares estimados ainda não são os efeitos marginais, ou seja, não representam o impacto de uma variável unitária do regressor sobre a probabilidade de interesses, como apontado por Greene (2008), mas somente dão a direção que segue a variação no logit estimado dada variação no regresso referente, fazendo necessário, nesse sentido, calcular o efeito marginal. Dessa forma, o efeito marginal médio (MEM) está expresso na tabela $n^{\circ} 4$.

O Efeito Marginal Médio evidencia que ceteris paribus, o aumento de um ano na idade acarreta na diminuição de aproximadamente 31 pontos percentuais na probabilidade de o indivíduo pertencer a uma EEEP. Ser do sexo masculino também diminui essa probabilidade em cerca de 1,31 pontos percentuais em comparação às mulheres. Possuir pai com escolaridade de até ensino fundamental e mãe com escolaridade de até ensino fundamental diminui a probabilidade de interesse, o primeiro em 32 pontos percentuais. As medidas socioeconômicas dos alunos e a que capta a condição da escola também aumentam a probabilidade de pertencer à escola profissionalizante em aproximadamente 18 pontos percentuais. 
Tabela 4: Efeito Marginal Médio do Logit

\begin{tabular}{cccc}
\hline & $\mathbf{d y} / \mathbf{d x}$ & Desvio Padrão & p-valor \\
\hline idade & -0.312053 & 0.011378 & 0.000 \\
tp_sexo & -0.0131482 & 0.0025794 & 0.000 \\
tp_estado_civil & 0.0674417 & 0.0134724 & 0.000 \\
tp_cor_raça & 0.0019689 & 0.030778 & 0.522 \\
patefund & -0.322537 & 0.0031727 & 0.000 \\
psup & -0.012251 & 0.0062491 & 0.050 \\
matefund & -0.0397622 & 0.0030865 & 0.000 \\
msup & 0.0130464 & 0.0044675 & 0.003 \\
ate2sm & -0.0019409 & 0.0029112 & 0.505 \\
infra1 & 0.1825238 & 0.0108213 & 0.000 \\
nse1 & 0.1893115 & 0.0096989 & 0.000
\end{tabular}

Fonte: Elaboração própria.

\section{5) CONSIDERAÇÕES FINAIS}

O sistema educacional dos países pode ser considerado fator essencial que se reflete na representatividade destes perante o mundo, agregando para estabelecer sua maior competitividade e qualidade de vida. A busca pela educação de qualidade faz parte da objetividade de várias nações, sendo facilitada àqueles que têm maior estabilidade financeira, mas também por aquelas que procuram um desenvolvimento mais completo e sustentável.

Dentre as diversas políticas educacionais, o ensino profissionalizante ganhou espaço e foi estabelecido em diversos países. A condição de garantir ao mesmo tempo o foco no conteúdo básico educacional do ensino médio e possibilitar a especialização em áreas de trabalho foi fonte de atratividade e de contrárias opiniões. Uma das concepções mais tratadas se refere à dualidade da concepção que o ensino profissionalizante era voltado somente aos pobres enquanto os mais ricos, não preocupados com especialização antecipada, voltavam-se ao ensino regular que dava ênfase ao ingresso na universidade. Fato que no Brasil procurou ser desmitificado quando diretrizes 
educacionais procuraram dar ao ensino profissionalizante também foco na preparação para entrada no ensino superior.

A critério de educação profissional este trabalho tratou das Escolas Estaduais de Ensino Profissionalizante (EEEP) do estado do Ceará que há quase dez anos passaram a ser realidade aos alunos da rede pública de ensino. Além da expectativa por trás de fatos empíricos como a maior representatividade das EEEP entre as escolas com as melhores notas no ENEM e a elevação do estado do Ceará no ranking nacional (SILVA, 2013), pesquisas recentes mostraram que de fato os alunos das escolas profissionalizantes do estado apresentam melhor desempenho no ENEM e assim maiores chances de adentrar no ensino superior (MARIANO; ARRAES; BARBOSA, 2016), além de menores chances de estar trabalhando durante o ensino médio (MARIANO; ARRAES; SOUZA, 2015).

Não foi aqui, contudo, estabelecido o objetivo de negar a possibilidade das raízes que firmaram o ensino profissionalizante ou avaliar o impacto direto dessa política, mas apresentar os fatores que podem explicar os alunos realizarem esse tipo de ensino. Dessa forma, foram utilizados dados do INEP e da SEDUC para captar as variáveis a respeito dos alunos da rede pública de ensino do estado do Ceará para o ano de 2013 e aplicar um modelo logit para explicar o aluno fazer parte de uma EEEP. Fatores pessoais, nível educacional dos pais, de condição socioeconômica e de infraestrutura das escolas foram utilizados para explicar a probabilidade de inserção nesse tipo de ensino.

Como resultados, pode-se destacar que quanto maior a idade menor é a probabilidade de fazer parte do ensino profissionalizante. De fato, poder-se-ia esperar uma relação inversa entre essas variáveis, pois a maior idade pode ser considerada fator que indique que os alunos tenham que trabalhar ao mesmo tempo em que cursam o ensino médio, o que provavelmente impediria que ele estudasse em uma EEEP, haja vista que o ensino é de tempo integral. Ainda sobre as variáveis que representam características pessoais dos alunos e baseado também em estudos sobre a educação, é atendida a expectativa a priori de relação direta entre o logit e o aluno ser branco e solteiro, enquanto que, se o aluno for do sexo masculino, diminui a probabilidade de este fazer parte da educação profissional. Contudo, a variável raça e renda de até dois salários mínimos não foram significativas ao modelo.

A educação dos pais foi em tudo significativa para explicar o aluno cursar o ensino profissionalizante e mostrou que o fato de a mãe possuir o ensino superior pelo menos incompleto aumenta a probabilidade considerada 
em cerca de 1,30 pontos percentuais, enquanto as variáveis que dizem respeito à educação dos pais diminuem a chance de o aluno fazer parte das EEEP. A variável indicadora de o pai ter apenas o fundamental completo, por exemplo, diminui a probabilidade de interesse em cerca de 32 pontos percentuais. As chances de o aluno pertencer à escola profissionalizante, no entanto, aumentam quanto maior o índice de condição socioeconômica do aluno e de infraestrutura da escola.

Através das especificidades encontradas foi possível reconhecer características dos estudantes da rede pública e seu ingresso em um tipo de realidade educacional ainda recente tanto para o estado do Ceará quanto para o Brasil. Espera-se que as determinações auxiliem políticas que visem melhor atender à população, especialmente os jovens, visando a um sistema educacional mais inclusivo e que minimize as dificuldades do ensino público. É levantada a importância de estudos que continuem a buscar características das práticas de ensino, avaliem o impacto da política profissionalizante e que essa possa ser utilizada como exemplo de novas práticas incluindo às escolas regulares. 


\section{REFERÊNCIAS}

ANDRADE, E. C. SchoolAccountability no Brasil: experiências e dificuldades. Revista de Economia Política. São Paulo, v. 28, n. 3, p. 443-453, jul.- set. 2008. Disponível em: < http://www.scielo.br/pdf/rep/v28n3/a05v28n3.pdf>.

ARAÚJO, A. J. N.; CHEIN, F.; PINTO, C. Ensino Profissionalizante, Desempenho Escolar e Inserção Produtiva: Uma Análise com dados do ENEM. 2014. Disponível:< http://www.anpec.org.br/encontro/2014/submissao/files_I/i12ac3a8f487db438fc6278e117ab46 8a01.pdf >.

BARROS, R. P.; LIMA L. Avaliação de impacto de programas sociais: Por que, para que e quando fazer? Avaliação Econômica de projetos sociais. São Paulo: Dinâmica Gráfica Editora, 2012. ed. 1, p. 13-29. Disponível em: < http://www.fundacaoitausocial.org.br/_arquivosestaticos/FIS/pdf/livro_aval_econ.pdf $\gg$.

BROOKE, N. O futuro das Políticas de Responsabilidade Educacional no Brasil. Cadernos de Pesquisa. Minas Gerais, v. 36, n.128, p. 377-401, mai.- ago. 2006. Disponível em: < http://www.scielo.br/pdf/cp/v36n128/v36n128a06.pdf>

CARNOY, M.; LOEB, S.; SMITH, T.L. Do Higher State Test Scores in Texas Make for Better High School Outcomes? CPRE Report Series. Pennsylvania, nov. 2001. Disponível em: < http://cepa.stanford.edu/sites/default/files/rr47.pdf $>$.

CASTRO, M.H.G.; TIEZZI, S. A reforma do ensino médio e a implantação do ENEM no Brasil. In: BROCK, C.; SCHWARTZMAN, S. (Org.). Os desafios da educação no Brasil. Rio de Janeiro: Nova Fronteira, 2005. p. 119-154. Disponível em: < http://www.schwartzman.org.br/simon/desafios/4ensinomedio.pdf >

FOLEY, P. The Socio-Economic Status of Vocational Education and Training Students in Australia. National Centre for Vocational Education Research Ltd. PO Box 8288, Stational Arcade, Adelaide, SA 5000, Australia, 2007.

GREENE, W. H. Econometric Analysis. 6 ed. Pearson Prentice Hall. Upper Saddle River. New Jersey, 2008.

GUJARATI, D. N.; PORTER, D. C. Econometria Básica, 5 ed. Porto Alegre: AMGH, 2011. $924 \mathrm{p}$.

MARIANO, Z.; ARRAES, R. A.; SOUZA, N. O. Desempenho escolar e inserção no mercado de trabalho: Uma avaliação das Escolas Estadual de Ensino Profissionalizantes (EEEP) do Ceará. In: BARRETO, F. A. F. D.; MENEZES, A. S. B.; ASSIS. D. N. C.; SOUSA, F. J. (Orgs). Economia do Ceará em Debate 2015. Fortaleza: IPECE, 2015. p. 75-107.

MARIANO, Z.; ARRAES, R. A.; BARBOSA, R. B. Análise Longitudinal para Avaliação do Ensino Profissionalizante. XII Encontro Economia do Ceará em Debate. Fortaleza: IPECE, 2016. Disponível em: 
http://www2.ipece.ce.gov.br/encontro/2016/trabalhos/An\%C3\%A1lise\%20Longitudinal\%20pa ra\%20Avalia\%C3\%A7\%C3\%A3o\%20do\%20Ensino\%20Profissionalizante.pdf

MARTINS, A. P. Pressupostos de Gramsci na educação profissional e tecnológica de nível médio. Revista de Educação, Ciência e Tecnologia, v. 1, n. 2, 2012.

MOEHLECKE, S. O Ensino Médio e as novas diretrizes curriculares nacionais: entre recorrências e novas inquietações. Revista Brasileira de Educação, v. 17, n. 49, Rio de Janeiro. Jan- abril, 2012. Disponível em: < http://www.scielo.br/scielo.php?pid=S141324782012000100003\&script=sci_arttext $>$.

SEDUC, Secretaria de Educação do Ceará. Disponível em: http://www.seduc.ce.gov.br/index.php/educacao-profissional

SEVERNINI, E. R.; ORELLANO, V. I. F. O efeito do ensino profissionalizante sobre a probabilidade de inserção no mercado de trabalho e sobre a renda no período pré-Planfor. Revista Economia, Brasília(DF), v.11, n.1, p.02-20, jan/abr 2010.

SILVA, V. H. O. Análise da Participação das Escolas Públicas Estaduais Cearenses no Exame Nacional do Ensino Médio (ENEM): 2009-2011. IPECE Informe, n. 54. Fortaleza, 2013. Disponível em:

$<$ http://www.ipece.ce.gov.br/publicacoes/ipeceinforme/Ipece_Informe_54_26_fevereiro_2013. pdf $>$.

TAVARES, P. A. Três Ensaios em Economia da Educação. São Paulo, 2014. Disponível em: $<$

http://bibliotecadigital.fgv.br/dspace/bitstream/handle/10438/11542/Tr\%C3\%AAs\%20Ensaios $\% 20 \mathrm{em} \% 20$ Economia $\% 20$ da $\% 20$ Educa $\%$ C3\%A7\%C3\%A3o.pdf? sequence $=1 \&$ is Allowed= >Acesso em: 12 junho 2015.

VIEIRA, S.L. Gestão, avaliação e sucesso escolar: recortes da trajetória cearense.

EstudosAvançados, São Paulo, v.21, n.60, 2007.

WOOLDRIDGE, J. M. Econometric analysis of cross section and panel data. 2 ed. Cambridge, MA: The MIT Press, 2010. 